\title{
A Note on Moral Insanity and Psychopathic Disorders
}

\author{
F. A. WhITLOCK, Professor of Psychiatry, University of Queensland, Australia
}

Despite a good deal of argument to the contrary (Maughs, 1941; Hunter and Macalpine, 1963; Walk, 1954; Walk and Walker, 1961; Craft, 1965; Whitlock, 1967) it is still commonly believed that Prichard's 'moral insanity' (1835) was the forerunner of our present-day concept of psychopathic (sociopathic) personality; the most recent example of this appearing in the paper by Davies and Feldman (1981), who write: 'In 1801 Pinel described a condition termed by him manie sans délire, the notable feature of which was that the sufferer showed bouts of extreme violence but with no signs of psychosis ... Prichard confirmed Pinel's observation and coined the term "moral insanity" which led to "a marked perversion of the natural impulses".' A number of modern textbooks (Sim, 1974; Friedman et al, 1975; Slater and Roth, 1977; Trethowan, 1979) also appear to regard moral insanity as the precursor of psychopathic disorder, although Trethowan correctly noted how the word 'moral' denoted 'affective' and was not being used in the usual ethical sense. He went on, however, to write that Prichard described cases showing antisocial or even criminal behaviour.

A careful examination of the cases mentioned by Pinel (1801) and by Prichard should make it abundantly clear that except for the first of the three patients cited by Pinel, there was not the remotest resemblance between their examples and what today would be classed as psychopathic personality. Nor do the authors' general delineations of the disorder conjure up the picture of present-day psychopathy.

Why, one might ask, has the error persisted? One might conjecture that few of the writers who maintain the identity of moral insanity and psychopathy have troubled to refer to the original texts. Another source of confusion is the word 'moral' as used in the early part of the 19th century. Walk (1954) and Craft (1965) comment on how 'moral' was employed in three ways: as psychological in, for instance, 'moral treatment' or moral causes of insanity; as affective or emotional as opposed to intellectual or rational; and in the ethical sense of right or wrong. Walk and Craft find that Prichard used the term throughout his treatise to describe cases of insanity whose emotional and affective faculties were disturbed, and only later, and incidentally, used it in the ethical sense. 'It is hardly justifiable,' Craft writes, 'to attribute the first description of psychopathy to Prichard on the strength of this one passage.'

Of Pinel's three patients given as examples of manie sans délire-'délire' here meaning delusion (or 'illusion' as Prichard calls it) - the first appears to have had a life-long propensity for unbridled violence and impulsive behaviour originating in childhood. In the absence of any data on possible cerebral damage as a cause of this behaviour, it is likely that he would be classed as an aggressive psychopath today. The second patient was probably subject to attacks of temporal lobe epilepsy with characteristic epigastric sensations rising into the neck and head, but without proceeding to a grand mal convulsion. He was a man of good character, well aware of his tendency to violence during these episodes, and made every effort to avoid harming others by warning them of his attacks. The third patient, the one who was liberated by a mob to whom he appeared rational, but then became infected by the prevailing excitement and laid about him with a sword with fatal effects, was almost certainly suffering from mania as now understood.

Prichard's cases were also diagnostically heterogenous. They included cases of mania, manic-depressive psychosis, epilepsy, obsessional neurosis, two possible schizophrenics and a 46-year-old man who almost certainly was showing early signs of dementia. None of these patients had shown life-long antisocial behaviour. The case descriptions abound in testimonials to the patients' previous good character-'a gentleman remarkable for the warmth of his affections'; 'her natural disposition was steady and industrious'; 'a man of sober and domestic habits'; and so on. Only one, a probable manic, could be said to have been aggressive and irascible. During his illness he assaulted a clergyman of his parish, but he made a complete recovery without residual defect.

Faced by diagnoses of this kind one has to search for some common feature which united them under the rubric of moral insanity. One thing is certain; antisocial, aggressive and criminal behaviour were conspicuously absent in individuals who, until their illnesses, had led blameless lives. Taking Pinel's concept of manie sans délire as a guide, Prichard was clearly describing individuals with major affective ('moral') disturbances without 'any remarkable disorder or defect of the intellect, of knowing and reasoning faculties, and particularly without any insane illusion or hallucination.' Their conduct is disturbed as well as their feelings, but these symptoms are closely allied: 'Propensities are so nearly allied to passions and emotions that they are generally referred to the same division of the faculties. In my classification, disorders of [both] are comprehended under the designation of Moral Insanity.'

In fact Prichard brings out this widely diverse symptomatology, with absence of intellectual disorder as the only common link, in the following passage: 'The varieties of moral insanity are perhaps as numerous as the modifications of feeling or passion in the human mind. The most frequent forms, however, of the disease are those which are characterized either by the kind of excitement already described or by the opposite state of melancholy dejection. One of these is, in many instances, a permanent state, but there are cases in which they alternate or supersede each other... 
The prevalent character of the disorder is sometimes derived from the constitutional disposition of the individual, but there are instances in which it is strikingly different from this natural temperament.' Again, in his later book (1847) Prichard wrote, 'The existence of moral insanity is palpable and easily recognized only in those instances in which it comes on, as it often does, after some strongly marked disorder affecting the brain and the general state of health, such as a slight attack of paralysis and when it displays a state of mind strikingly different from the previous habitual and natural character of the individual.'

Moreover, in Prichard's view, if a patient suffering from moral insanity developed some delusional idea, the case became one of monomania. He introduces such cases, classified as monomania, as being ones in which 'the actual supervention of erroneous belief or illusion on a previously existing moral insanity was clearly marked and admitted of no doubt', and as illustrating 'the connection between the two forms of diseases and the transition from one into the other'.

Thus it is clear that, with few exceptions, the cases of moral insanity described by Prichard, were individuals who, until they developed behavioural and affective changes, had not been noteworthy for antisocial or other unacceptable behaviour. It would be rare for our contemporary psychopath to be awarded such a character reference as those mentioned above - $a$ far cry from the individual whose propensities have often been observed in late childhood and adolescence and generally do not remit over a short period of time with full recovery of normal behaviour.

For an account of the evolution of moral insanity into psychopathic disorder the reader is referred to an excellent one by Maughs (1941). However, some additional points are worth mentioning.

At the time when Prichard was writing, legal concepts of insanity required a demonstration of disturbances of reason as shown by the presence of delusion. As Battie (1758) and Erskine in Hadfield's case (1800) remarked, 'Delusion is the very hallmark of insanity'. Consequently, individuals who committed offences while suffering from affective disorders but not exhibiting delusion (illusion) or hallucination would be unable to plead insanity in their defence. Understandably, when psychiatrists of the day introduced the term 'moral insanity' in their evidence, judges assumed that the word was being used in its ethical sense and disliked it on the ground that it could lead to pleas of irresistible impulse. How, one might ask, was moral insanity to be distinguished from ordinary depravity?

It was a point which Maudsley considered (1874) without reaching any very clear-cut conclusions. None the less, he did not generally see moral insanity as a life-long disorder, for he observed how "there has been an alteration in the temper and habit in consequence of disease or of a sufficient cause of disease'. He also wrote, 'Perhaps the strongest evidence of the nature of moral insanity as a disease of the brain is furnished by the fact that its symptoms sometimes precede for a time the symptoms of intellectual derangement in a severe case of undoubted insanity as, for example, a case of acute mania or of general paralysis or of senile dementia'. He continued: 'It is interesting indeed to notice that at least one of Dr Prichard's cases, on which he founded his description of the disease, was really a case of general paralysis'. Maudsley was probably incorrect, as the patient in question, who made a good recovery, was almost certainly suffering from mania.

After elaborating further on the nature of the problem, he wrote: 'In the most typical case of moral insanity which has come under my observation there had been previous attacks of melancholia, and it is upon one of these that the moral derangement directly followed. Such cases commonly end in dementia, the disease of the mind passing into destruction thereof.' Here again the range of conditions this author described can be diagnosed without difficulty as examples of recognizable clinical disorders, for the most part devoid of psychopathic features of long duration.

These comments bring up a second point of importance. It is quite clear that writers like Prichard, Maudsley and Hack Tuke $(1885 ; 1892)$ were convinced that moral insanity generally developed on a background of brain disease, including epilepsy or affective psychosis. Tuke wrote (1885) 'the cases recorded ... afford examples of morbid cerebral conditions in which the mental symptoms displayed are the emotional and the most automatic rather than those concerned in cognition and may be referred to the form of mental derangement usually termed moral insanity, although the moral sentiments may themselves be free from disease' (my italics).

Tuke (1892), like Maudsley, was clearly puzzled by examples of moral insanity diagnosed in individuals involved in criminal proceedings, but he warned against an excessive preoccupation with its association with crime and went on to discuss cases characterized by sudden attacks of depression for no cause as well as abnormal behaviour as the precursors of coarse brain disease. This is in marked contrast to the ideas of modern writers on psychopathy; Scott (1960) specifically excluded individuals with epilepsy, organic brain disease and psychosis from his criteria for such a diagnosis.

None the less, it has to be admitted that during the 19th century opinions about the nature of moral insanity were divided and confused. Some authors widened the concept to include individuals with life-long tendencies to commit antisocial and criminal acts attributed to some innate failure of development of 'the moral faculty'. They could have found some support in the one passage in Prichard's later book (1847) in which, very tentatively, he suggests something of the kind. He says: 'It may be worth while to remark, though it is not easy to apply the observation to any practical advantage, that many of those instances in which the whole character of an individual through life has been noted for recklessness and abandoned depravity are perhaps in reality 
cases of moral madness ... I have alluded to this merely for completeness and scarcely in the most distant expectation of any practical result.'

By the turn of the century 'moral' was thought of entirely in the sense of 'ethical', but at last a distinction was being drawn between acquired 'moral insanity' and congenital 'moral imbecility', to which category these life-long deviants were now assigned. 'Moral idiocy or imbecility' had already been included by Skae (1863) in his famous 'aetiological' classification. He described his group as consisting of cases of 'congenital moral perversion, instinctive cruelty, destructiveness and theft'. He continued: 'Many of our most noted kleptomaniacs have been moral imbeciles; in fact, as far as I know, all have been so; and when we meet with kleptomania in cases of insanity it is only one of many symptoms.' The two categories appear separately in the classification adopted by the Medico-Psycological Association and the Lunacy Commissioners. The Radnor Commission of 1904-08 had before it evidence of the existence of both disorders, with suggested definitions. In their Report they quoted that proposed for moral insanity by Drs Savage and Mercier on behalf of the Royal College of Physicians as follows:

A morally insane person means a person who, after many years of reputable life, all at once unaccountably exhibits vicious propensities or takes to criminal courses.

Also one proposed by Sir James Crichton-Browne, more organically slanted:

A morally insane person is one who, by reason of disease or disorder of the brain, has undergone a change of character manifested in a course of vicious or criminal conduct without obvious impairment of intellect.

Sir James also proposed a definition of moral imbecility, which the Commission considered admirable:

The moral imbecile is a person who by reason of arrested development or disease of the brain dating from birth or early years displays at an early age vicious or criminal propensities which are of an incorrigible or unusual nature and are generally associated with some slight limitation of intellect.

The Commission did not think it necessary to make moral insanity a separate legal category, but moral imbecility (later renamed moral deficiency) was incorporated in the 1913 Mental Deficiency Act.

Both terms, moral insanity and moral defect subsequently fell into disrepute, but it is the latter group of cases that more clearly was the precursor of our contemporary antisocial psychopath. It is arguable that, had this gradual transformation from moral insanity via moral deficiency to psychopathy not occurred, psychiatry today would not be saddled with the thankless task of trying to treat individuals who can hardly be said to be either 'insane' or 'imbecile' in any generally accepted sense.

\section{REFERENCES}

BATTIE, W. (1758) A Treatise on Madness. London: Whiston and White.

Craft, M. (1965) Ten Studies into Psychopathic Personality, pp. 7 9. Bristol: John Wright.

Davies, W. \& Feldman, P. (1981) Diagnosis of psychopathy by forensic specialists. British Journal of Psychiatry, 138, 329. 31.

Friedman, A., Kaplan, H. I. \& Sadock, B. J. (1975) Comprehensive Textbook of Psychiatry, 2nd Edition, $p$. 1287. Baltimore: Williams and Wilkins.

HADFIELD, J., case of (1800) 27 State Trials. 1281.

Hunter, R. \& MACAlPINE, I. (1963) Three Hundred Years of Psychiatry, pp. 836-39. Oxford University Press.

LeIGH, D. (1961) The Historical Development of British Psychiatry, pp. 172-84. Oxford: Pergamon.

Maudsley, H. (1874) Responsibility in Mental Disease. London: Henry S. King.

MAUGHS, S. (1941) Concepts of psychopathy and psychopathic personality: Its evolution and historical development. Journal of Criminal Psychopathology, 2, 329; 426.

PINeL, P. (1801) A Treatise on Insanity. Trans. 1806 by D. D. Davies, Republished 1962, pp. 150-56. New York: Hafner.

Prichard, J. C. (1835) A Treatise on Insanity. London: Sherwood, Gilbert and Piper.

- (1847) On the Different Forms of Insanity in Relation to Jurisprudence. London: Hippolyte Baillière.

RAdNor Commission (1908) Report of the Royal Commission on the Care and Control of the Feeble-Minded, Vol. VIII, pp 189f. HMSO.

ScoTt, P. D. (1960) The treatment of psychopaths. British Medical Journal, $i, 1641-46$.

Sim, M. (1974) Guide to Psychiatry, 3rd Edition, p. 429. Edinburgh: Churchill Livingstone.

SKAE, D. (1863) A rational and practical classification of insanity. Journal of Mental Science, 9, 309-19.

Slater, E. \& Roth, M. (1977) Clinical Psychiatry, 3rd Edition, p. 56. London: Baillière Tindall and Cassell.

Trethowan, W. H. (1979) Psychiatry, 4th Edition, p. 273. London: Baillière Tindall.

TUKE, D. H. (1885) Moral and emotional insanity. Journal of Mental Science, 31, 174; 366.

- (1892) Dictionary of Psychological Medicine, pp. 813-16. London: Churchill.

WALK, A. (1954) Some aspects of the 'moral treatment' of the insane. Journal of Mental Science, 100, 809.

— \& WALKER, D. L. (1961) Gloucester and the beginnings of the RMPA. Journal of Mental Science, 107, 609-11.

WhrtLock, F. A. (1967) Prichard and the concept of moral insanity. Australian and New Zealand Journal of Psychiatry, 1, 72-79. 